\title{
Inhibition of postnatal maternal performance in rats treated with marijuana extract during pregnancy
}

\author{
E. L. ABEL, N. DAY, B. A. DINTCHEFF, and C. A. S. ERNST \\ Research Institute on Alcoholism, Buffalo, New York 14203
}

\begin{abstract}
Neonatal rats raised by dams treated with marijuana extract during pregnancy gained less weight and reared significantly less in an open field than neonates raised by nondrug-treated dams.
\end{abstract}

Although prenatal exposure to marijuana or $\Delta^{9}$-THC (the psychoactive component in marijuana) does not generally produce congenital malformations in animals (cf. Fleischman, Hayden, Rosenkrantz, \& Braude, 1975), there is evidence that in utero exposure to marijuana or $\Delta^{9}$.THC may produce retardation of postnatal development and behavioral teratogenesis (e.g., Borgen, Davis, \& Pace, 1973; Vardaris, Weisz, Fazel, \& Rawitch, 1976). However, because offspring are generally raised by their own mothers after birth in such studies, in utero drug exposure, postnatal impairment of maternal behavior, and impairment of lactational performance are potentially confounded (cf. Abel, 1975; Borgen et al., 1973).

The present study was therefore conducted to determine if treatment of adult rats with marijuana during pregnancy would affect postnatal development of nondrug-exposed neonates assigned to them.

\section{METHOD}

Sixty eight primiparous Long-Evans rats (Blue Spruce Farms, Altamont, New York) approximately 100 days of age were divided into four groups. Group 1 was intubated with $10 \mathrm{mg} / \mathrm{kg} / \mathrm{day}$ of crude marijuana extract. Group 2 was intubated with $150 \mathrm{mg} / \mathrm{kg} / \mathrm{day}$ of marijuana extract. Group 3 was intubated with vehicle only (olive oil) and was pair- and waterfed with Group 2. Group 4 constituted a nontreated ad-lib control group. Drug treatments commenced on Day 3 of pregnancy and continued until delivery of pups.

In addition to the experimentally treated animals, an equal number of pregnant animals were designated as "surrogate" mothers. These animals were not disturbed until they gave birth.

As soon as the animals in the experimentally treated groups gave birth, their offspring were removed and replaced by six pups born to the surrogate-treated mothers. (No drug treatment was administered after birth.) Measures of pup weights were determined on postnatal Days 1, 7, 14, and 21. On Days 28-30, 13 males and 13 females were randomly selected from each group and individually placed for $3 \mathrm{~min}$ in the center of an open field marked off in squares. Records were kept of latency to move from the center square, total number of squares crossed, number of rears, and defecation.

\section{RESULTS}

Body weight data for pups are presented in Figure 1. Differences in body weight were dose dependent. Pups

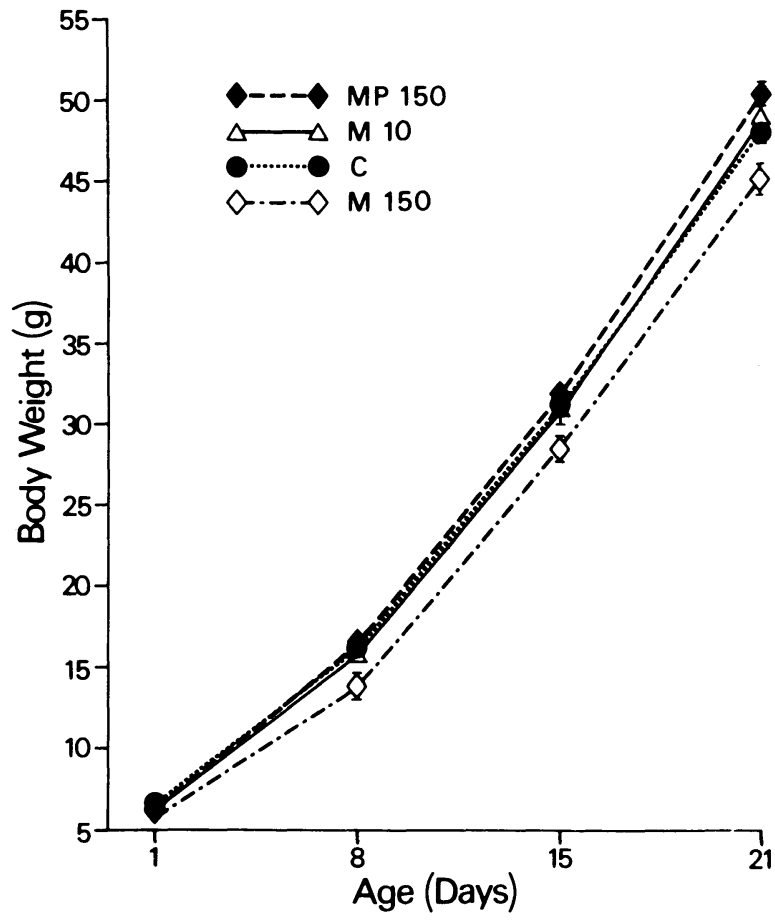

Figure 1. Changes in body weights of neonatal pups raised by dams treated with 10 or $150 \mathrm{mg} / \mathrm{kg} / \mathrm{day}$ of marijuana extract (M) during pregnancy, pair-fed controls (MP 150), and ad-lib nondrug-treated controls (C).

raised by dams given the large dose of marijuana during pregnancy weighed the least, followed by pups raised by animals given the low dose of marijuana. Groups did not differ significantly from each other on Day 1 . However, on Days 7, 14, and 21, Group 2 animals (mothers receiving marijuana $150 \mathrm{mg} / \mathrm{kg} /$ day) weighed significantly less than pair-fed controls (Group 3) and Group 1 animals (mothers receiving marijuana $10 \mathrm{mg} / \mathrm{kg} /$ day). Pups raised by dams pair-fed to Group 2 animals did not differ significantly from pups raised by mothers allowed ad-lib access to food and water. The groups and days factors were both significant $[F(3,64)=6.69, p<.001$; $F(3,192)=5,037.63, p<.001]$, as was the Groups by Days interaction $[F(9,192)=2.24, p<.02]$. 
Group differences in postnatal mortality were significant $\left[\chi^{2}(3)=27.77, p<.001\right]$. Significantly more pups raised by Group 2 mothers died, as compared with those raised by Group 1 mothers $\left[\chi^{2}(1)=7.12\right.$, $\mathrm{p}<.01]$ or those raised by Group 3 pair-fed controls $\left[\chi^{2}(1)=24.92, p<.001\right]$. Mortality differences between the offspring of pair-fed and ad-lib mothers were not significant.

The only measure of open-field behavior on which groups were significantly different was rearing $[F(3,96)=$ $2.84, \mathrm{p}<.04]$. Group means (and SEs) were 16.6(1.5), 13.9 (1.3), 19.5 (1.8), 18.6 (1.3) for Groups 1, 2, 3, and 4 , respectively. Neither sex nor the Group by Sex interaction was significant.

\section{DISCUSSION}

Even though Groups 1 and 2 dams were not exposed to marijuana postnatally, the surrogate offspring assigned to these animals exhibited a dose-related decrease in postnatal growth and an inhibition of rearing behavior in the open field.
These data demonstrate the importance of removing offspring from their biological mothers and fostering them as soon as possible to "surrogate" nondrug-treated mothers. Failure to do so precludes unequivocal assessment of prenatal exposure to drugs such as marijuana on postnatal growth and development.

\section{REFERENCES}

Abel, E. L. Suppression of maternal behavior in the mouse by $\Delta^{9}$-tetrahydrocannabinol. Federation Proceedings, 1975, 34, 2968.

Borgen, L. A., Davis, W. M., \& Pace, H. B. Effects of prenatal $\Delta^{9}$-tetrahydrocannabinol on the development of rat of fspring. Pharmacology, Biochemistry and Behavior, 1973, 1, 203-206.

Fleischman, R. W., Hayden, D. W., Rosenkrantz, H., \& Braude, M. C. Teratogenic evaluation of $\Delta^{9}$-tetrahydrocannabinol in mice, including a review of the literature. Teratology, 1975, 12, 47-50.

Vardaris, R. M., Weisz, D. J., Fazel, A., \& Rawitch, A. B. Chronic administration of delta-9-tetrahydrocannabinol to pregnant rats: Studies of pup behavior and placental transfer. Pharmacology, Biochemistry and Behavior, 1976, 4, 249-254.

(Received for publication August 14, 1979.) 